\title{
Prevalence of sleep-disordered breathing after stroke and TIA
}

\section{A meta-analysis}

Andrea Seiler, MD, Millene Camilo, MD, PhD, Lyudmila Korostovtseva, MD, PhD, Alan G. Haynes, PhD, Anne-Kathrin Brill, MD, Thomas Horvath, MD, Matthias Egger, MD,* and Claudio L. Bassetti, MD*

Neurology ${ }^{\circledR}$ 2019;92:e648-e654. doi:10.1212/WNL.0000000000006904

\section{Abstract \\ Objective}

To perform a systematic review and meta-analysis on the prevalence of sleep-disordered breathing (SDB) after stroke.

\section{Methods}

We searched PubMed, Embase (Ovid), the Cochrane Library, and CINAHL (from their commencements to April 7, 2017) for clinical studies reporting prevalence and/or severity of SDB after stroke or TIA. Only sleep apnea tests performed with full polysomnography and diagnostic devices of the American Academy of Sleep Medicine categories I-IV were included. We conducted random-effects meta-analysis. PROSPERO registration number: CRD42017072339.

\section{Results}

The initial search identified 5,211 publications. Eighty-nine studies (including 7,096 patients) met inclusion criteria. Fifty-four studies were performed in the acute phase after stroke (after less than 1 month), 23 studies in the subacute phase (after 1-3 months), and 12 studies in the chronic phase (after more than 3 months). Mean apnea-hypopnea index was 26.0/h (SD 21.7-31.2). Prevalence of SDB with apnea-hypopnea index greater than $5 / \mathrm{h}$ and greater than $30 / \mathrm{h}$ was found in $71 \%$ ( $95 \%$ confidence interval $66.6 \%-74.8 \%$ ) and $30 \%$ (95\% confidence interval $24.4 \%-35.5 \%$ ) of patients, respectively. Severity and prevalence of SDB were similar in all examined phases after stroke, irrespective of the type of sleep apnea test performed. Heterogeneity between studies $\left(I^{2}\right)$ was mostly high.

\section{Conclusion}

The high prevalence of SDB after stroke and TIA, which persists over time, is important in light of recent studies reporting the (1) feasibility and (2) efficacy of SDB treatment in this clinical setting.

\author{
Correspondence \\ Prof. Bassetti \\ claudio.bassetti@insel.ch
}

\footnotetext{
*These authors contributed equally to this work as last authors.

From the Sleep Wake Epilepsy Center (A.S., M.C., L.K., A.-K.B., T.H., C.L.B.), and Departments of Neurology (A.S., M.C., L.K., T.H., C.L.B.) and Pulmonary Medicine (A.-K.B.), Bern University Hospital, University of Bern, Switzerland; Neurology Division (M.C.), Department of Neuroscience and Behavioral Sciences, Ribeirão Preto School of Medicine, University of São Paulo, Brazil; Hypertension Department (L.K.), Somnology Group, Almazov National Medical Research Center, St. Petersburg, Russia; and CTU Bern (A.G.H.), and Institute of Social and Preventive Medicine (A.G.H., M.E.), University of Bern, Switzerland.

Go to Neurology.org/N for full disclosures. Funding information and disclosures deemed relevant by the authors, if any, are provided at the end of the article.
} 


\section{Glossary}

AHI = apnea-hypopnea index; CI = confidence interval; SDB = sleep-disordered breathing.

Increasing evidence demonstrates a consistent association between sleep-disordered breathing (SDB) and vascular morbidity and mortality. ${ }^{1-3}$ Besides being associated with cardiovascular risk factors, SDB independently increases the risk of stroke in the general population and is associated with other risk factors such as hypertension and atrial fibrillation. ${ }^{4-6}$ Furthermore, stroke patients with SDB seem to be more prone to early neurologic worsening, ${ }^{7}$ longer hospital stays, ${ }^{8}$ and worse cognitive and functional recovery compared to stroke patients without SDB. ${ }^{9,10}$ The prevalence of SDB is high in patients with stroke and TIA and was found to be $72 \%$ for an apnea-hypopnea index (AHI) of greater than $5 / \mathrm{h}$ in a meta-analysis published in $2010{ }^{11}$ Existing randomized controlled trials indicate that continuous positive airway pressure may have a positive effect on neurologic recovery, especially in the first week after stroke. ${ }^{12}$

Consequently, in 2014, the American Heart Association/ American Stroke Association stroke guidelines included for the first time the recommendation for sleep apnea screening in patients with ischemic stroke or TIA (recommendation Class IIb, level of evidence B). ${ }^{13}$ Performing routine polysomnographies in patients with acute stroke is difficult because of availability and environmental circumstances. Outpatient waiting lists for polysomnographies in the chronic stroke phase are also causing diagnostic delays. In the last decade, the use of limited-channel sleep apnea tests has facilitated SDB diagnosis in patients with stroke. Thus, more studies have been performed in this field. In this meta-analysis, we provide an update on prevalence and severity of SDB after stroke and TIA at different diagnostic time points and using different types of sleep apnea tests.

\section{Methods}

This meta-analysis is reported according to the general guidelines outlined in the PRISMA (Preferred Reporting Items for Systematic Reviews and Meta-Analyses) statement. ${ }^{14}$ The study protocol has been registered on PROSPERO (crd.york.ac.uk/PROSPERO/; registration number CRD42017072339).

\section{Search strategy}

We systematically searched PubMed, Embase, the Cochrane Library, and CINAHL (Cumulative Index to Nursing and Allied Health Literature) from their respective inceptions to April 2017 for studies assessing the prevalence and severity of SDB in persons after hemorrhagic stroke, ischemic stroke, or TIA. We searched free text words and medical subject headings. Terms describing the study population were combined with specific terms for SDB. Details on the search strategy and platforms can be found in data available from Dryad (appendix e-1, doi.org/10.5061/dryad.n76v191). To identify additional trials, we searched the World Health Organization International Clinical Trials Registry Platform and ClinicalTrials.gov. We also screened the reference lists of included articles to find additional studies relevant to this review.

\section{Study selection}

Study selection was performed independently by 2 reviewers (L.K., M.C.) who initially identified studies for full-text review based on titles and abstracts. Then the eligible articles were selected based on predefined inclusion and exclusion criteria (see the table for a full list of inclusion and exclusion criteria). In short, we considered original observational or interventional studies in adults with ischemic stroke, hemorrhagic stroke, or TIA reporting prevalence of SDB. The language of included studies was limited to English, German, French, Russian, Portuguese, Spanish, and Italian. In case of disagreement about the inclusion of a study, the judgment of a third reviewer (A.S.) was decisive.

\section{Data extraction}

Three reviewers (A.S., L.K., M.C.) independently extracted data, with differences resolved by consensus. The prespecified data extraction sheet included demographics, sleep apnea test characteristics, prevalences of sleep-associated respiratory events (AHI, respiratory disturbance index, or oxygen desaturation index) $>5 / \mathrm{h},>20 / \mathrm{h}$, and $>30 / \mathrm{h}$, and average counts of AHI, obstructive apnea indices, and central apnea indices. We decided to use these thresholds because the diagnosis of SDB in patients with stroke is currently given from an AHI $>5 / \mathrm{h},{ }^{15}$ whereas therapy in studies is often started with AHI $>20 / \mathrm{h}$, and SDB is considered to be severe (and linked with increased cardiovascular morbidity) from $\mathrm{AHI}>30 / \mathrm{h}$. ${ }^{1}$

The diagnostic sleep apnea tests were classified according to the American Academy of Sleep Medicine as either type I (full facility-based polysomnography), type II (same channels as full polysomnographies, but unattended), type III (portable limited-channel device with 2 respiratory variables, oxygen saturation, and a cardiac variable), or type IV (portable limited-channel device with 1 or 2 parameters; use of the diagnostic mode of an automatic positive airway pressure system was marked separately). ${ }^{16}$ If the type of diagnostic procedure was heterogeneous within one study, the study was assigned to the group of the technically simpler device to avoid overestimation of data quality. We further noted the definition of hypopnea that was used for scoring. In addition, we extracted the type of cerebrovascular event (TIA, ischemic, or hemorrhagic stroke), stroke etiology according to the TOAST (Trial of Org 10172 in Acute Stroke Treatment) classification, ${ }^{17}$ stroke localization (supra- and infratentorial), and latency of the diagnostic study from stroke onset. According 
Table PICO table for sleep-disordered breathing after stroke

\begin{tabular}{|c|c|}
\hline Population & $\begin{array}{l}\text { Studies including adults (older than } 18 \text { y) with a stroke (ischemic or hemorrhagic) or TIA, diagnosed by qualified personnel (in an } \\
\text { emergency department, stroke center, department of neurology, or similar unit) }\end{array}$ \\
\hline \multirow{9}{*}{$\begin{array}{l}\text { Intervention or } \\
\text { exposure }\end{array}$} & Studies that used diagnostic testing for sleep-disordered breathing (devices with at least 2 channels, one of which is oximetry) \\
\hline & Inclusion criteria \\
\hline & Observational and experimental original studies in human adults \\
\hline & $\begin{array}{l}\text { Studies including at least } 10 \text { individuals with stroke or TIA, which reported prevalence of sleep-disordered breathing (as AHI, RDI, } \\
\text { or ODI) }\end{array}$ \\
\hline & Exclusion criteria \\
\hline & $\begin{array}{l}\text { Studies not published as full reports (review, meta-analysis, editorial, letter, protocol, unpublished data, conference abstract, } \\
\text { thesis, dissertation, in-press manuscript, case report) }\end{array}$ \\
\hline & $\begin{array}{l}\text { Preselected high-risk populations for sleep-disordered breathing; populations that have already been diagnosed with sleep- } \\
\text { disordered breathing }\end{array}$ \\
\hline & Additional publications from included trials \\
\hline & Articles in languages other than English, German, Italian, Spanish, Portuguese, French, and Russian \\
\hline Comparison & Not applicable \\
\hline \multirow[t]{2}{*}{ Outcome } & Prevalence of sleep disordered breathing: percentage of patients with AHI per hour of $>5,>20$, or $>30$ \\
\hline & Mean AHI overall \\
\hline
\end{tabular}

Prevalence and mean AHI according to phase after stroke: acute ( $<1 \mathrm{mo})$, subacute (1-3 mo), and chronic (>3 mo) phase

Abbreviations: $\mathrm{AHI}=$ apnea-hypopnea index; $\mathrm{ODI}=$ oxygen desaturation index; $\mathrm{PICO}$ = population, intervention, comparison, outcome; $\mathrm{RDI}=$ respiratory disturbance index.

to the latency, studies were categorized into acute (less than 1 month after stroke), subacute (1-3 months), and chronic (more than 3 months after stroke) phase. Studies for which time of evaluation had not been precisely declared were classified within the group most plausible according to the study's text.

\section{Quality assessment}

Because the types of included studies were very heterogeneous, no validated tool for the assessment of the study quality could be applied. Nevertheless, we recorded the applied criteria for stroke severity, diagnostic criteria of SDB, the number of patients included from all the patients fulfilling inclusion criteria, as well as characteristics of the population such as stroke severity, age, and other inclusion or exclusion criteria. We further assessed whether sleep apnea tests were attended or unattended, had a minimum duration and had been analyzed manually or automatically (accounting for detection bias), and whether cardiac or pulmonary comorbidities and medication, representing possible confounding factors, had been taken into consideration.

\section{Statistical analysis}

We provide a quantitative synthesis of the findings from the included studies (mean and SD or percent with 95\% confidence interval $[\mathrm{CI}]$ ) by using random-effects meta-analyses to account for study heterogeneity. When studies did not provide a mean value (e.g., for AHI), the median was used where available. Where SD was missing, it was estimated by using 25th and 75th percentiles. ${ }^{18}$ Average counts and SDs of individual studies were transformed to CIs before analysis and transformed back afterward, which resulted in asymmetrical CIs. ${ }^{19}$ We assessed between-trial heterogeneity by calculating the $I^{2}$ statistic $^{20}$ as a measure of the proportion of total variation in estimates that is attributable to heterogeneity, where $I^{2}$ values of $25 \%, 50 \%$, and $75 \%$ correspond to low, moderate, and high degrees of heterogeneity. Publication bias was assessed using the Egger regression test and funnel plots. ${ }^{21}$ We used the meta package in $\mathrm{R}$ (version 3.3.2; R Foundation for Statistical Computing, Vienna, Austria) to analyze data. ${ }^{22,23}$

\section{Data availability}

Any data not published within the article are available from Dryad (appendices, doi.org/10.5061/dryad.n76v191).

\section{Results}

\section{Study characteristics}

The initial search identified 5,211 publications. After screening of titles and abstracts, we retrieved 417 articles as full text. Of these, 86 met our inclusion criteria. Three of the included studies reported prevalence of SDB longitudinally from 2 different time points after stroke, ${ }^{24-26}$ which results in a total of 89 datasets (7,096 patients). The process of identifying eligible studies is summarized in figure 1. Appendices e-2.1 to e-2.3 (doi.org/10.5061/dryad.n76v191) summarize the characteristics of included studies. A list of the 330 excluded full texts with reasons for exclusions is available from the authors on request. 
Figure 1 Flow diagram of search strategy and study selection

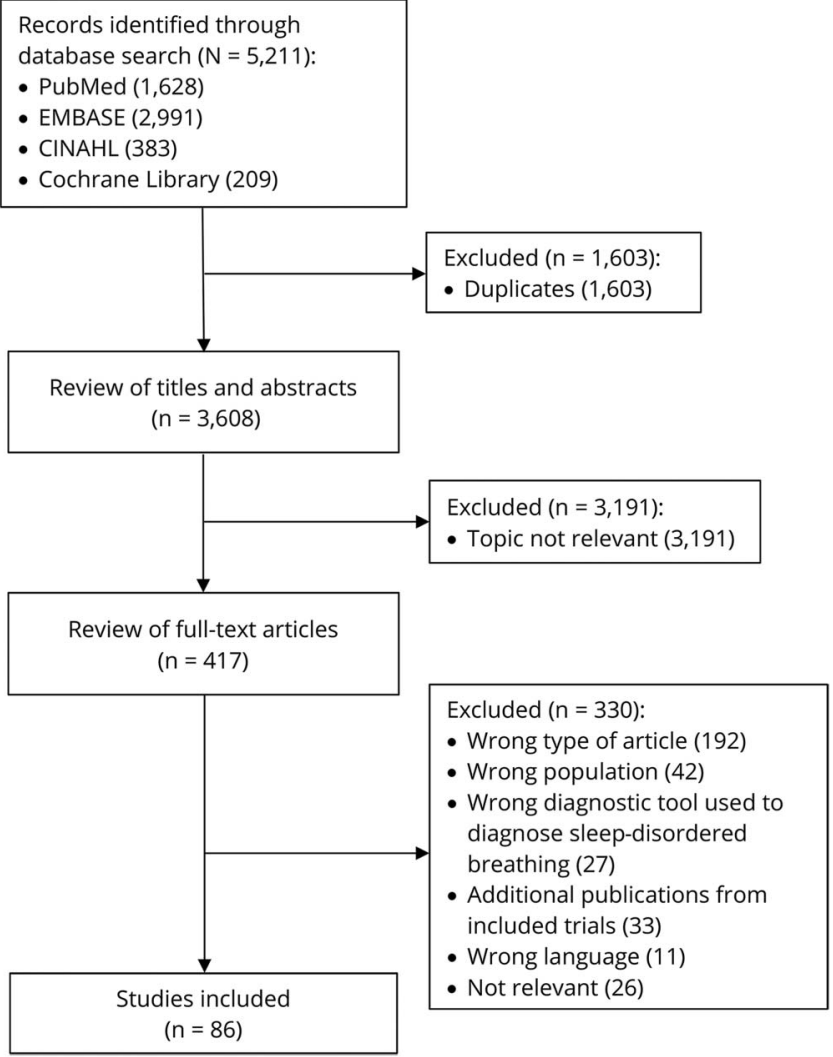

Last search: April 7, 2017.

Most of the studies were published after the year 2000 and have been performed in Europe, the United States, or Canada. Thirteen studies (15\%) have been located in Asian countries, 3 (3\%) in South America, and 3 (3\%) in Australia. Sixty-one studies $(71 \%)$ included hospitalized patients, 23 (27\%) took place in a rehabilitation unit, and $2(2 \%)$ recruited patients from a community-based ambulatory cohort.

A total of 54 studies (61\%) have been performed in the acute phase after stroke (4,545 patients, i.e., $64 \%$ of total), 23 (26\%) in the subacute phase (1,993 patients, i.e., $28 \%$ of total), and $12(13 \%)$ in the chronic phase (558 patients, i.e., $8 \%$ of total). The earliest time point for assessment of SDB was during the first night after stroke ${ }^{7,27-29}$; the latest diagnostic studies have been performed after a mean of 826 days following stroke. ${ }^{30}$

Overall, 5,275 patients ( $74 \%$ of total) had an ischemic stroke, 302 ( $4 \%$ of total) had a hemorrhagic stroke, 405 ( $6 \%$ of total) had a TIA, and for 1,188 patients ( $16 \%$ of total), the type of the cerebrovascular event was not reported.

In 41 studies (49\%), full polysomnography was used as diagnostic tool (sleep apnea tests type I or II), 34 studies (39\%) used limited-channel devices (type III), 2 studies (2\%) used limited-channel devices (type IV), and 9 studies (10\%) used the diagnostic mode of an automatic positive airway pressure device. The definition of hypopnea was variable (data available from Dryad, appendix e-2, doi.org/10.5061/dryad. n76v191).

The overall prevalence of SDB with an AHI $>5 / \mathrm{h}$ was $71 \%$ (95\% CI 66.6\%-74.8\%), $40 \%$ for an AHI $>20 / \mathrm{h}$ (95\% CI $33.45 \%-46.85 \%$ ), and $30 \%$ for an AHI $>30 / \mathrm{h}$ (95\% CI $24.4 \%-35.5 \%)$ with a high between-study heterogeneity. Prevalences were similar at all 3 analyzed prespecified latencies from stroke onset (figure 2), but there were generally fewer studies available for the prevalence of SDB in the chronic phase after stroke, with a larger range of SD. The overall prevalence of central sleep apnea ( $\geq 50 \%$ of total apneas scored as central) with an $\mathrm{AHI}>5 / \mathrm{h}$ was $12 \%$ (95\% CI 5.5\%-23.4\%). There were no data available to calculate the prevalence of central sleep apnea with an AHI $>20 /$ h or $>30 / h$.

Studies using a hypopnea definition based on desaturation only did not yield a significantly higher prevalence of AHI $>5 / \mathrm{h}$ $(70 \%)$ or $>30 / \mathrm{h}(29 \%)$ than those based on either desaturation or arousal $(60 \% \mathrm{AHI}>5 / \mathrm{h}, 38 \% \mathrm{AHI}>30 / \mathrm{h} ; p=0.286$ for AHI $>5 / \mathrm{h}, p=0.15$ for AHI $>30 / \mathrm{h}$ ). Prevalence of AHI $>5 / \mathrm{h}$ was significantly higher in studies using a minimal desaturation of $3 \%$ for hypopneas (83\%) compared to those using 4\% (64\%; $p=$ 0.003 ) but not significantly different for AHI $>30 / \mathrm{h}$ ( $45 \%$ of patients when $3 \%$ desaturation was used, $54 \%$ when $4 \%$ desaturation was required; $p=0.619$ ). However, both results have to be interpreted with caution, as they are mainly driven by 2 studies with a small sample size. ${ }^{31,32}$

Figure 2 Prevalence of $\mathrm{AHI}>5 / \mathrm{h},>20 / \mathrm{h}$, and $>30 / \mathrm{h}$ for the acute, subacute, and chronic phase after stroke or TIA

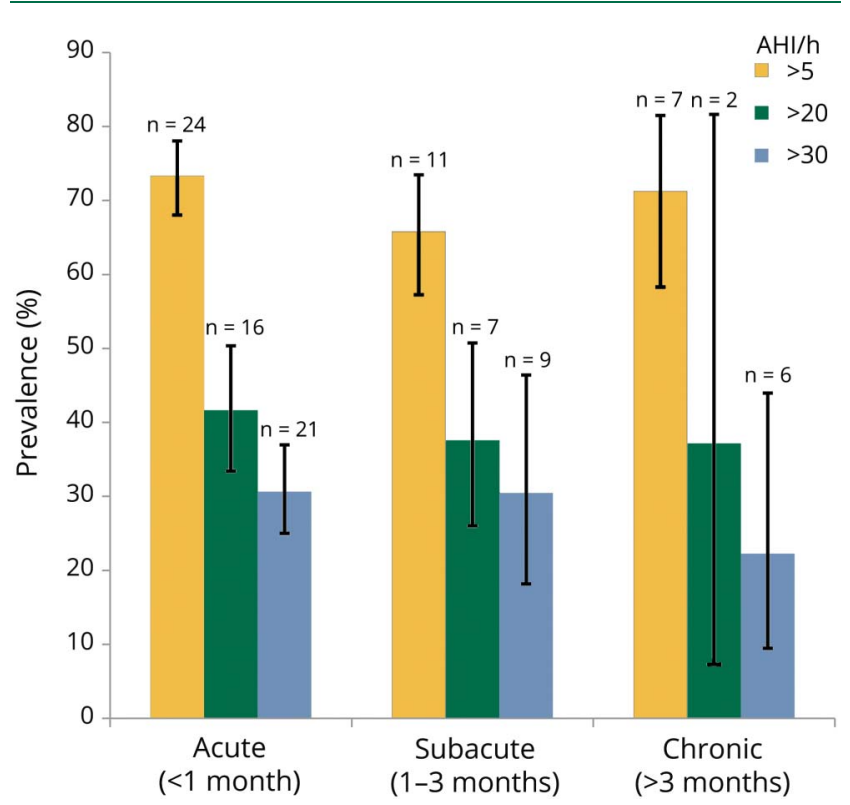

Prevalence in percentage of all included patients across the studies with 95\% confidence interval. $\mathrm{AHI}=$ apnea-hypopnea index; $\mathrm{n}=$ number of studies available. 
The overall mean AHI for all included studies and all time points was 26.0/h (95\% CI 21.7-31.2, $\mathrm{n}=44, I^{2} 24 \%$ ) (figure 3), the mean obstructive apnea index was 11.7/h (95\% CI 6.5-21.1, $\left.\mathrm{n}=12, I^{2} 32 \%\right)$, the mean central apnea index was $5.3 / \mathrm{h}(95 \% \mathrm{CI}$ $\left.2.8-10.0, \mathrm{n}=13, I^{2} 12 \%\right)$, and all the other events were hypopneas, adding up to the overall mean AHI. The analysis of the different time points showed a mean AHI of $25.0 / \mathrm{h}$ (95\% CI $\left.20.23-30.9, \mathrm{n}=28, I^{2} 0 \%\right)$ in the acute phase after stroke. There

Figure 3 Forest plot of mean AHI in the acute, subacute, and chronic phase after stroke

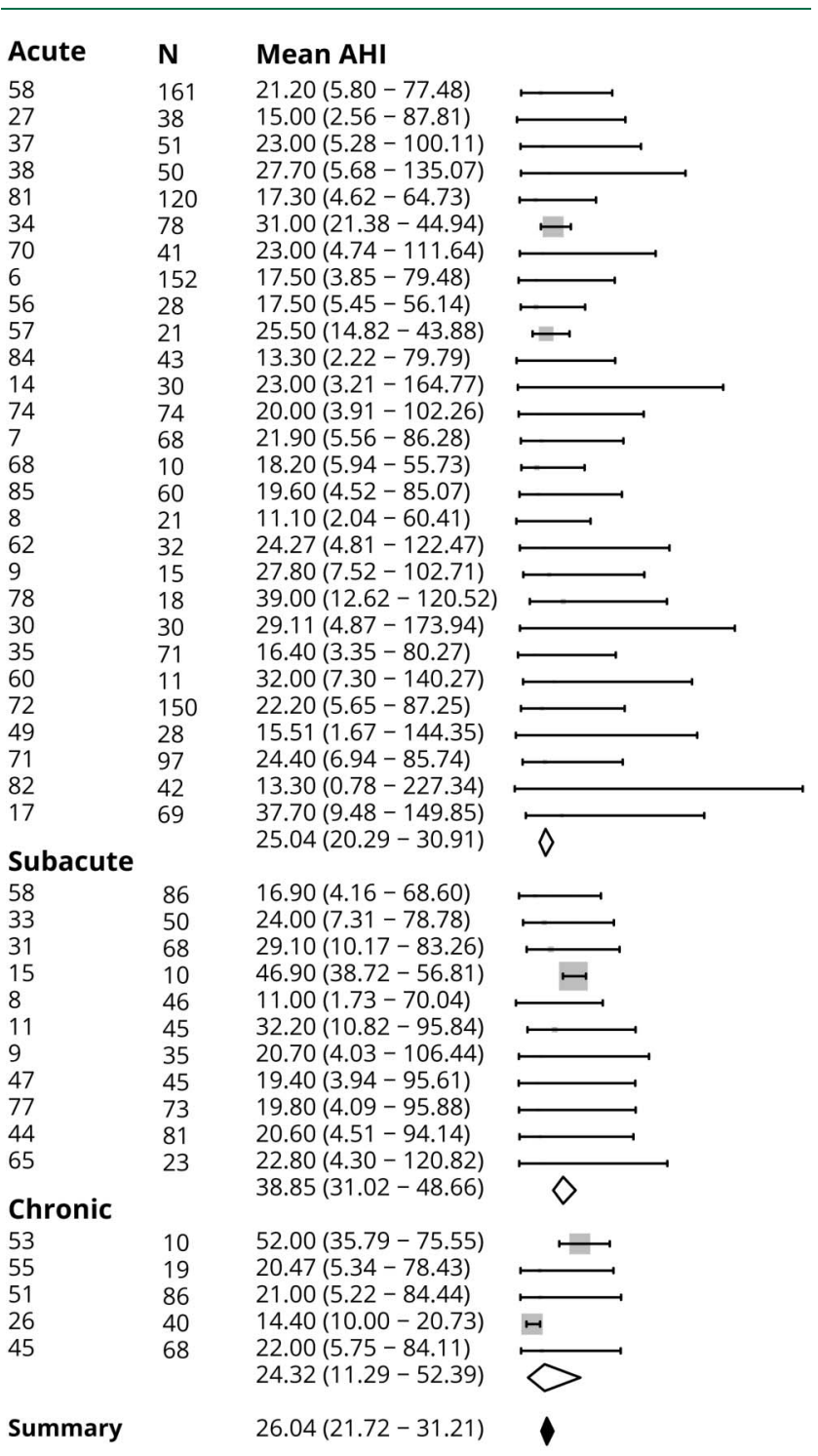

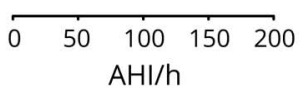

The numbers in the first column refer to the reference numbers in data available from Dryad (appendix e-5, doi.org/10.5061/dryad.n76v191). Only studies reporting mean value are included. The horizontal lines and blocks represent the mean $\mathrm{AHI}$ with $95 \%$ confidence intervals for each study. The width of the blocks represents the relative weight of the study in the average effect. The center of the diamonds is the pooled point estimate of the studies included for each phase after stroke. The width of the diamonds represents the $95 \%$ confidence interval of the pooled mean value. $\mathrm{AHI}=$ apnea-hypopnea index. was a higher mean $\mathrm{AHI}$ in the subacute phase (mean AHI 38.9/ h, 95\% CI 31.0-48.7, $\mathrm{n}=11, I^{2} 3.0 \%$ ), which was statistically significant compared to the acute and chronic phase in the random-effects model $(p=0.017)$. However, looking at the forest plot (figure 3 ) and the relative weight of the studies in the average effect, there is one study with a small sample size and a very small SD that has strongly influenced this result. ${ }^{31}$

The analysis of the different diagnostic tools that were used to examine the patients revealed a slightly higher mean AHI in the studies using polysomnography (mean AHI 25.7/h, 95\% CI 17.3-34.2) compared to portable limited-channel devices (mean AHI 22.9/h, 95\% CI 16.9-28.9), but the difference did not reach statistical significance $(p=0.148)$.

A summary of the quality assessment of the included studies can be found in data available from Dryad (appendices e- 3 and e-4, doi.org/10.5061/dryad.n76v191). Almost all studies excluded patients with severely decreased consciousness or other severe medical comorbidities. Seven studies had additional inclusion criteria for maximum severity of strokes. About half $(n=44)$ of the studies did not explicitly exclude patients with known cardiac or lung disease. For their sleep apnea test, 16 studies required a minimum duration of registration from 1 to 6 hours. Most of the studies were unattended. About half of the sleep apnea tests have at least partly been manually scored. Seven studies mentioned use of sedative medication in their exclusion criteria. A few studies $(n=8)$ excluded central sleep apnea. We noted funnel plot asymmetries for the prevalence of AHI $>5 / h,>20 / h$, and $>30 / \mathrm{h}$. The Egger test indicated publication bias for the overall mean AHI $(p<0.001)$ and for the prevalence of SDB with an AHI $>5 / \mathrm{h}(p<0.001)$ but not for the mean AHI of studies including only ischemic patients $(p=0.485)$, the prevalence of SDB with an AHI $>20 / \mathrm{h}(p=0.507)$, and the prevalence of SDB with an $\mathrm{AHI}>30 / \mathrm{h}(p=0.674)$.

\section{Discussion}

Our large standardized meta-analysis of 89 datasets with a total of 7,096 patients shows a high prevalence of SDB after stroke and TIA with $70 \%$ of patients having an $\mathrm{AHI}>5 / \mathrm{h}$ and one-third of patients having severe SDB (AHI >30/h). This major finding confirms the results of the smaller 2010 published meta-analysis (29 studies with a total of 2,343 patients). ${ }^{11}$

The pathophysiologic mechanisms of SDB in patients with stroke and TIA are still not completely understood. In some patients, SDB is probably preexisting; changes of upper airway patency and increased supine positioning poststroke may also contribute. A recent study in the general population using a 3\% threshold for the definition of hypopnea found an AHI of more than $5 / \mathrm{h}$ in $84 \%$ of men and $61 \%$ of women, which equals our results. ${ }^{33}$ As these authors point out, these percentages are, however, higher than those seen in studies using a $4 \%$ threshold. $^{34-37}$ 
Although the prevalence of SDB in stroke survivors is high in our meta-analysis, the following circumstances could have even led to an underestimation of SDB: first, most of the analyzed studies were biased toward mildly affected stroke patients and they explicitly excluded patients with severe comorbidities, who would be expected to have more risk factors for SDB than healthier individuals. Second, patients with known SDB as well as patients with central sleep apnea have been excluded in many trials. Contrariwise, the potential confounding effects of sedating medication have not been considered by most of the studies and could possibly have increased the AHI in some individuals. ${ }^{38}$

Mean AHI also remained constantly high from the acute to the subacute and chronic phase after stroke. The finding of an even slightly higher mean $\mathrm{AHI}$ in the subacute compared to the acute and chronic phase after stroke could mainly be attributed to one small study, so that we can assume an almost constant course. In group comparisons, we could therefore not confirm a tendency of a decrease of apneas over time, which has been reported by longitudinal studies. ${ }^{25,26,39,40}$ This might be attributable to our cross-sectional study design and the heterogeneity of the studies in our meta-analysis. A constant prevalence of SDB has been described after TIA but not after stroke in 2 patient series from the same study authors. ${ }^{24,25}$ We could not separately analyze TIA and stroke patients in our study because of limited data. Concerning the type of apneic events, we demonstrated a predominance of obstructive over central apneas in mean AHI, which confirms previous reports of mainly obstructive sleep apnea after cerebrovascular events and is also in line with recent findings for the general population..$^{33,41}$

Comparing the mean AHI yielded by polysomnography (sleep apnea test type I and II) and limited-channel devices (sleep apnea test type III and IV), which has resulted in nonsignificant differences, reinforces the impression that screening of SDB can be performed in the clinical routine with respiratory polygraphy, which has proven to be feasible in previous studies. ${ }^{42,43}$ Despite this successful use of limitedchannel devices in patients with acute and postacute stroke, it has to be considered that validation studies against polysomnography have been performed in patients with stroke only for one special acoustic device and otherwise rely on comparative studies in the general population. ${ }^{1,44}$

Our results have to be interpreted in the light of the following limitations: there was a large methodologic and statistical heterogeneity between the studies. This consists of different inclusion criteria, different AHI cutoffs, missing reporting of stroke severity or lesion size in most studies, the application of variable definitions for hypopnea, and partial use of the oxygen desaturation index instead of AHI. Furthermore, validity of the reports' apnea counts are limited by the absence of minimal duration criteria (as opposed to the recommendation of the American Academy of Sleep Medicine ${ }^{16}$ ) and by the lack of visual correction of sleep apnea test scoring in several trials. Moreover, there was statistical evidence for publication bias. Smaller studies tend to report higher values for AHI and higher prevalence of mild SDB (AHI $>5 / h$ ). However, the funnel plots did not indicate that elimination of these studies would change our results. External validity is further limited as most of the studies included were from tertiary care centers and thus not based on the general population.

A limitation of our method is the statistical approach to a meta-analysis of average counts, which have been treated as if they were normally distributed rather than Poisson distributed. As this was caused by a lack of alternative approaches, we could not correct for this. In addition, the assignment of the studies into our chosen phases after stroke has proved difficult in some cases, particularly when the latency between stroke and sleep apnea test was highly variable within one study. Furthermore, the use of a statistical test to compare the AHI for our chosen phases after stroke is challenging because some individuals may have contributed to more than one time point.

SDB in patients with stroke is frequent irrespective of the latency after stroke onset. For clinical routine, limited-channel devices appear to be promising tools to estimate SDB severity in this clinical setting. Their use is expected to facilitate and accelerate the identification of patients with SDB at limited costs. Recent studies reporting the feasibility and efficacy of SDB treatment in stroke/TIA justify the recommendation for a rapid screening of SDB in the stroke unit. ${ }^{12,45,46}$

\section{Author contributions}

A. Seiler: study concept and design, acquisition, analysis and interpretation of data, writing of the manuscript. M. Camilo: study concept and design, acquisition of data, revision of the manuscript. L. Korostovtseva: study concept and design, acquisition of data, revision of the manuscript. A.G. Haynes: statistical analysis, interpretation of data. A.-K. Brill: study concept and design, interpretation of data, revision of the manuscript. T. Horvath: study concept and design, interpretation of data, revision of the manuscript. M. Egger: study concept and design, interpretation of data, revision of the manuscript. C.L. Bassetti: study concept and design, analysis and interpretation of data, revision of the manuscript. All authors have seen and approved the final version.

\section{Acknowledgment}

The authors thank Beatrice Minder and Doris Kopp, from the Institute of Social and Preventive Medicine, University of Bern, Switzerland, for their independent literature search. They also thank the authors who answered e-mails and provided relevant information about their studies and study populations.

\section{Study funding}

Swiss National Science Foundation grants 320030-149752 and 320030-125069. 


\section{Disclosure}

The authors report no disclosures relevant to the manuscript. Go to Neurology.org/N for full disclosures.

\section{Publication history}

Received by Neurology March 9, 2018. Accepted in final form December $14,2018$.

\section{References}

1. Jonas DE, Amick HR, Feltner C, et al. Screening for obstructive sleep apnea in adults: evidence report and systematic review for the US Preventive Services Task Force. JAMA 2017;317:415-433.

2. Dong JY, Zhang YH, Qin LQ. Obstructive sleep apnea and cardiovascular risk: metaanalysis of prospective cohort studies. Atherosclerosis 2013;229:489-495.

3. Javaheri S, Barbe F, Campos-Rodriguez F, et al. Sleep apnea: types, mechanisms, and clinical cardiovascular consequences. J Am Coll Cardiol 2017;69:841-858.

4. Redline S, Yenokyan G, Gottlieb DJ, et al. Obstructive sleep apnea-hypopnea and incident stroke: the Sleep Heart Health Study. Am J Respir Crit Care Med 2010;182:269-277.

5. Yaggi HK, Concato J, Kernan WN, Lichtman JH, Brass LM, Mohsenin V. Obstructive sleep apnea as a risk factor for stroke and death. N Engl J Med 2005;353:2034-2041.

6. Munoz R, Duran-Cantolla J, Martínez-Vila E, et al. Severe sleep apnea and risk of ischemic stroke in the elderly. Stroke 2006;37:2317-2321.

7. Iranzo A, Santamaría J, Berenguer J, Sánchez M, Chamorro A. Prevalence and clinical importance of sleep apnea in the first night after cerebral infarction. Neurology 2002; 58:911-916.

8. Kaneko Y, Hajek VE, Zivanovic V, Raboud J, Bradley TD. Relationship of sleep apnea to functional capacity and length of hospitalization following stroke. Sleep 2003;26:293-297.

9. Yan-fang S, Yu-ping W. Sleep-disordered breathing: impact on functional outcome of ischemic stroke patients. Sleep Med 2009;10:717-719.

10. Aaronson JA, van Bennekom CA, Hofman WF, et al. Obstructive sleep apnea is related to impaired cognitive and functional status after stroke. Sleep 2015;38:1431-1437.

11. Johnson KG, Johnson DC. Frequency of sleep apnea in stroke and TIA patients: a meta-analysis. J Clin Sleep Med 2010;6:131-137.

12. Brill AK, Horvath $\mathrm{T}$, Seiler A, et al. CPAP as treatment of sleep apnea after stroke: a meta-analysis of randomized trials. Neurology 2018;90:e1222-e1230.

13. Kernan WN, Ovbiagele B, Black HR, et al. Guidelines for the prevention of stroke in patients with stroke and transient ischemic attack: a guideline for healthcare professionals from the American Heart Association/American Stroke Association. Stroke 2014;45:2160-2236.

14. Moher D, Liberati A, Tetzlaff J, Altman DG. Preferred reporting items for systematic reviews and meta-analyses: the PRISMA statement. PLoS Med 2009;6:e1000097.

15. American Academy of Sleep Medicine. International Classification of Sleep Disorders, 3rd ed. Darien, IL: American Academy of Sleep Medicine; 2014.

16. Kapur VK, Auckley DH, Chowdhuri S, et al. Clinical practice guideline for diagnostic testing for adult obstructive sleep apnea: an American Academy of Sleep Medicine clinical practice guideline. J Clin Sleep Med 2017;13:479-504.

17. Adams HP Jr, Bendixen BH, Kappelle LJ, et al. Classification of subtype of acute ischemic stroke. Definitions for use in a multicenter clinical trial. TOAST. Trial of Org 10172 in Acute Stroke Treatment. Stroke 1993;24:35-41.

18. Wan X, Wang W, Liu J, Tong T. Estimating the sample mean and standard deviation from the sample size, median, range and/or interquartile range. BMC Med Res Methodol 2014;14:135.

19. Quan H, Zhang J. Estimate of standard deviation for a log-transformed variable using arithmetic means and standard deviations. Stat Med 2003;22:2723-2736.

20. Higgins JP, Thompson SG. Quantifying heterogeneity in a meta-analysis. Stat Med 2002;21:1539-1558.
21. Egger M, Davey Smith G, Schneider M, Minder C. Bias in meta-analysis detected by a simple, graphical test. BMJ 1997;315:629-634.

22. R: A Language and Environment for Statistical Computing [computer program] Vienna: The R Foundation for Statistical Computing; 2011.

23. Schwarzer G. Meta: General Package for Meta-Analysis. R-package version 4.3-0; 2015.

24. Bravata DM, Concato J, Fried T, et al. Auto-titrating continuous positive airway pressure for patients with acute transient ischemic attack: a randomized feasibility trial. Stroke 2010;41:1464-1470.

25. Bravata DM, Concato J, Fried T, et al. Continuous positive airway pressure: evaluation of a novel therapy for patients with acute ischemic stroke. Sleep 2011;34:1271-1277.

26. Parra O, Arboix A, Bechich S, et al. Time course of sleep-related breathing disorders in first-ever stroke or transient ischemic attack. Am J Respir Crit Care Med 2000;161: 375-380.

27. Selic C, Siccoli MM, Hermann DM, Bassetti CL. Blood pressure evolution after acute ischemic stroke in patients with and without sleep apnea. Stroke 2005;36:2614-2618.

28. Siccoli MM, Valko PO, Hermann DM, Bassetti CL. Central periodic breathing during sleep in 74 patients with acute ischemic stroke: neurogenic and cardiogenic factors. J Neurol 2008;255:1687-1692.

29. Pontes-Neto OM, Fernandes RMF, Sander HH, et al. Obstructive sleep apnea is frequent in patients with hypertensive intracerebral hemorrhage and is related to perihematoma edema. Cerebrovasc Dis 2010;29:36-42.

30. Schäfer D, Gopon F, Sidiropoulou M, Schläfke ME, Greulich W. Polygraphic screening after ischemic stroke: a consecutive study on 258 patients. Somnologie 2001;5:135-140.

31. Brunner H. Success and failure of mirtazapine as alternative treatment in elderly stroke patients with sleep apnea: a preliminary open trial. Sleep Breath 2008 ; 12 : 281-285.

32. Mohsenin V, Valor R. Sleep apnea in patients with hemispheric stroke. Arch Phys Med Rehabil 1995;76:71-76.

33. Heinzer R, Vat S, Marques-Vidal P, et al. Prevalence of sleep-disordered breathing in the general population: the HypnoLaus study. Lancet Respir Med 2015;3:310-318.

34. Young T, Palta M, Dempsey J, Skatrud J, Weber S, Badr S. The occurrence of sleepdisordered breathing among middle-aged adults. N Engl J Med 1993;328:1230-1235

35. Quan SF, Howard BV, Iber C, et al. The Sleep Heart Health Study: design, rationale, and methods. Sleep 1997;20:1077-1085.

36. Bixler EO, Vgontzas AN, Lin HM, et al. Prevalence of sleep-disordered breathing in women: effects of gender. Am J Respir Crit Care Med 2001;163:608-613.

37. Peppard PE, Young T, Barnet JH, Palta M, Hagen EW, Hla KM. Increased prevalence of sleep-disordered breathing in adults. Am J Epidemiol 2013;177:1006-1014.

38. Jullian-Desayes I, Revol B, Chareyre E, et al. Impact of concomitant medications on obstructive sleep apnoea. Br J Clin Pharmacol 2017;83:688-708

39. Harbison J, Ford GA, James OF, Gibson GJ. Sleep-disordered breathing following acute stroke. QJM 2002;95:741-747.

40. Bassetti CL, Milanova M, Gugger M. Sleep-disordered breathing and acute ischemic stroke: diagnosis, risk factors, treatment, evolution, and long-term clinical outcome. Stroke 2006;37:967-972.

41. Hermann DM, Bassetti CL. Role of sleep-disordered breathing and sleep-wake disturbances for stroke and stroke recovery. Neurology 2016;87:1407-1416.

42. Kepplinger J, Barlinn K, Albright KC, et al. Early sleep apnea screening on a stroke unit is feasible in patients with acute cerebral ischemia. J Neurol 2013;260:1343-1350.

43. Boulos MI, Elias S, Wan A, et al. Unattended hospital and home sleep apnea testing following cerebrovascular events. J Stroke Cerebrovasc Dis 2017;26:143-149.

44. Ryan CM, Wilton K, Bradley TD, Alshaer H. In-hospital diagnosis of sleep apnea in stroke patients using a portable acoustic device. Sleep Breath 2017;21:453-460.

45. Tsivgoulis G, Alexandrov AV, Katsanos AH, et al. Noninvasive ventilatory correction in patients with acute ischemic stroke: a systematic review and meta-analysis. Stroke 2017;48:2285-2288.

46. Bravata DM, Sico J, Vaz Fragoso CA, et al. Diagnosing and treating sleep apnea in patients with acute cerebrovascular disease. J Am Heart Assoc 2018;7:e008841. 


\section{Neurology}

Prevalence of sleep-disordered breathing after stroke and TIA: A meta-analysis

Andrea Seiler, Millene Camilo, Lyudmila Korostovtseva, et al.

Neurology 2019;92;e648-e654 Published Online before print January 11, 2019

DOI 10.1212/WNL.0000000000006904

This information is current as of January 11, 2019

\section{Updated Information \&} Services

References

Permissions \& Licensing

Reprints including high resolution figures, can be found at: http://n.neurology.org/content/92/7/e648.full

This article cites 43 articles, 12 of which you can access for free at: http://n.neurology.org/content/92/7/e648.full\#ref-list-1

Information about reproducing this article in parts (figures,tables) or in its entirety can be found online at:

http://www.neurology.org/about/about_the_journal\#permissions

Information about ordering reprints can be found online:

http://n.neurology.org/subscribers/advertise

Neurology ${ }^{\circledR}$ is the official journal of the American Academy of Neurology. Published continuously since 1951, it is now a weekly with 48 issues per year. Copyright @ 2019 American Academy of Neurology. All rights reserved. Print ISSN: 0028-3878. Online ISSN: 1526-632X.

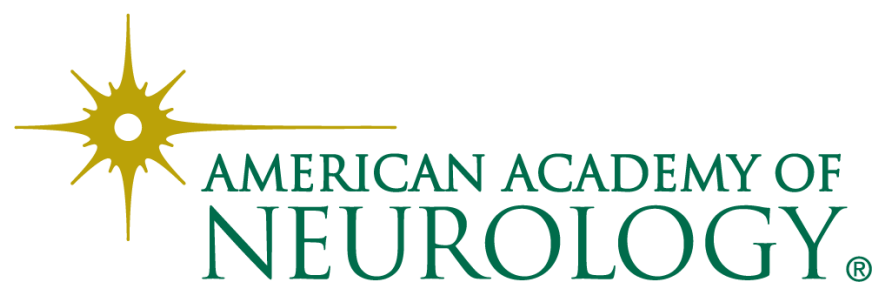

